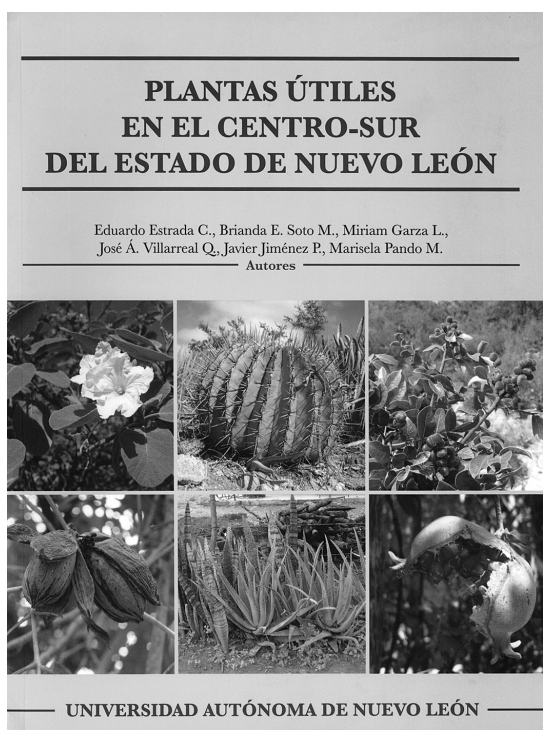

$\mathbf{E}$ ste trabajo pretende dar a conocer los usos de las diferentes plantas cultivadas y silvestres que ocurren en los distintos ecosistemas en el sur del estado de Nuevo León. Es el resultado de tres años de trabajo de campo. Los autores comentan que a pesar de la rica diversidad de plantas, con casi 3,200 especies de plantas vasculares registradas para el noreste de Nuevo León y sus asociaciones heterogéneas de plantas, que constituyen 13 principales comunidades, casi nada se conoce acerca de su utilidad, excepto el estudio llevado a cabo en el Parque Nacional Cumbres de Monterrey.

La flora total del estado ha sido contabilizada en aproximadamente 3,175 especies, englobadas en 1,031 géneros y 158 familias de plantas vasculares, con un claro predominio de dicotiledóneas. La región del sur del estado de Nuevo León comprende cinco municipios: Aramberri, Doctor Arroyo, Galeana, General Zaragoza y, Mier y Noriega. El estudio se llevó a cabo en tres de ellos: Aramberri $\left(2,809 \mathrm{~km}^{2}\right)$, Galeana $\left(6,740 \mathrm{~km}^{2}\right)$ y General Zaragoza $(1,289$ $\mathrm{km}^{2}$ ). Los tres municipios albergan una rica diversidad de climas, vegetación y flora, es el área donde se registran los picos montañosos más altos del noreste de México (Cerro El Potosí, Cerro Peña

\title{
Plantas útiles en el Centro-sur DEL ESTADO DE Nuevo LEÓN
}

\author{
Eduardo Estrada C., Brianda E. Soto M., Miriam Garza L., \\ José Á. Villatrreal Q., Javier Jiménez P., Marisela Pando M \\ Universidad Autónoma de Nuevo León. Facultad de Ciencias Forestales \\ Monterrey, México. 381 páginas. 2012. ISBN: 978-607-433-880-5
}

Nevada y Cerro El Viejo), y las comunidades de encino y coníferas más extensas del estado. De igual forma, comparten una gran área semiárida del Altiplano Mexicano, que es hogar de abundantes especies útiles.

Como en muchas otras regiones del país, en ésta se ha presentado pérdida del conocimiento etnobotánico, ya que las nuevas generaciones están migrando de la zona rural a la urbana como un medio de aspiración a una mejor calidad de vida desde el punto de vista económico. En total, se realizaron 102 encuestas abiertas a hombres y mujeres de diferentes edades, pero especialmente a personas mayores de 40 años, por ser aquellas que por su experiencia conocen más acerca del uso de las plantas. A cada persona se le preguntaba si conocía la planta (nombre común), para que se utiliza (medicinal, alimento, forraje, adorno, madera, fuego, construcción), como la utiliza (cocida, cruda, hervida, guisada, mezclada con otra), que parte de la planta utiliza (raíz, tallos, hojas, flores, frutos, semillas), cuando la utiliza (semanal, mensual, todo el año, de vez en cuando). Se visitaron áreas de zona templada, con predominio de bosques de conífera y encinos, así como zona árida y semiárida don- de predominan los tipos de matorral, especialmente aquellos constituidos por gobernadora, lechuguilla, hojasé, nopaleras, entre otros. En ambos ecosistemas se registraron todas las especies cultivadas y silvestres de la planta empleada. Toda la información etnobotánica recabada se procesó en una base de datos donde se clasificó a la planta por su uso. Además se colectó material botánico que le fue mostrado a las personas para corroborar su nombre común. Las plantas fueron identificadas con su nombre científico en el herbario CFNL de la Facultad de Ciencias Forestales, de la Universidad Autónoma de Nuevo León.

Las descripciones botánicas de las especies se basan en las plantas colectadas en el campo, en el mayor de los casos se agrega una descripción de las características distintivas de las especies para reconocerlas, asimismo se agregan fotografías de todas las especies para facilitar la identificación. La información de las especies se dispuso de manera alfabética con respecto a los nombres comunes, seguida por su nombre científico y la familia a la que pertenece. Las fotografías de las especies vegetales son originales, tomadas en el lugar donde crecen o en los lugares donde se almacena para 
su posterior uso; éstas fueron tomadas por Eduardo Estrada, Brianda Soto y Miriam Garza. Todas las que se presentan a lo largo de la obra son de muy buena calidad y nos dan una clara idea de las características de las plantas, en algunas de ellas aparecen representados algunos de los productos que se elaboran. Se incluye la distribución de la especie, se menciona, en el caso de las no cultivadas, los diferentes tipos de vegetación en donde se encuentran $\mathrm{y}$, con respecto a las plantas cultivadas se describe su origen.

Como en muchos de los estudios etnobotánicos llevados a cabo en el país, el uso medicinal es el que predomina; y en esta obra las descripciones de la parte utilizada, la forma de preparación y las enfermedades que curan son muy completas y concisas. Otros usos que se presentan a lo largo del libro son el comestible (en algunas ocasiones se refieren a fruto), cercos vivos, maderable, combustible (en algunas ocasiones se refieren a leña), ornamental, veterinario, forraje, bebidas, fibras etc. Falta un poco más de precisión en las categorías de uso. Cabe destacar el uso de diversas especies en la elaboración de escobas. Desde el punto de vista comestible destacan la palma samandoca (Yucca carnesorana) y la palma china (Yucca filifera), cuyas flores se preparan guisadas como alimento al igual que en muchas partes del país. Algunas especies destacan por su importancia y su gran cantidad de usos, como es el caso de la gobernadora (Larrea tridentata); lechuguilla (Agave lechuguilla); mesquite (Prosopis glandulosa); orégano, especie restringida en el noreste de México (Poliomintha longiflora); pino piñonero (Pinus cembroides); hojasé (Fluorensia cernua); sangre de grado (Jathropha dioica), candelilla (Euphorbia antisyphilitica), biznaga burra (Echinocactus platycanthus), entre otras.

Sin lugar a dudas, esta obra es una gran contribución al estudio de las plantas útiles de México y será de gran utilidad para poder ser consultada por los estudiosos de esta región del país y es punto de partida para que ellos profundicen en el tema. A partir de este catálogo se pueden hacer estudios en otros municipios y en otras regiones del estado de Nuevo León para lograr un análisis cuantitativo de la información generada. Es muy importante recopilar el conocimiento y uso de las plantas que diferentes grupos campesinos e indígenas de México han conservado a lo largo de generaciones y que en los últimos años ha disminuido su trasmisión.

\author{
Cristina Mapes \\ Jardín Botánico del Instituto \\ de Biología \\ Universidad Nacional Autónoma \\ de México, \\ México,D.F., México \\ cmapes@ib.unam.mx
}

